\title{
The Application of Traditional Culture in Industrial Design in New Epoch
}

\author{
Wu Shuang \\ Ningxia Institute of Science and Technology, 753000 NingXia,China
}

\begin{abstract}
This paper is based on industrial design, collation and analysis the Chinese traditional culture to expound the essentiality in design. From the perspective of design aesthetics to discuss the Chinese traditional cultural characteristics express under the background of the new era with artistic language, to provide new design ideas for industrial design with Chinese characteristics in the new era.
\end{abstract}

\section{Introduction}

Industrial design takes engineering, aesthetics, and economics as the basic elements. The rational design of the product's shape, structure, colour, and function is an organic combination of aesthetics and industrial technology. The rapid development of modern science and technology has provided new exhibition space for industrial design. Technical, scientific and functional features have all increased the sensory experience of design works for the public, but they have overlooked the aesthetic and cultural value.

As an ancient civilization with a long cultural history, China has a long history of culture. Traditional culture is rich in connotation, broad in subject matter, and possesses unique oriental cultural aesthetic interests. Fully understanding the role of traditional Chinese culture, extracting the aesthetic elements and essential characteristics of traditional culture, and organically integrating modern technology, and applying creative methods to industrial design is an important issue faced by modern designers. It is also an important link need to be reflection. A reasonable combination of these two aspects will not only increase the aesthetic value of the products, but also increase the cultural self-confidence and cultural soft power.

\section{The basic connotation of traditional culture}

Chinese traditional culture is a spiritual cultural heritage accumulated by the Chinese nation in long-term practice activities, and it is also a concrete manifestation of the unique way of thinking of the Chinese nation. The intersection of economic production methods, political systems, and patriarchal relations has formed the basic features of traditional Chinese culture.

The "Imagery" and "Symbolize" are the essence in Chinese traditional aesthetics and the concrete expression of the thinking mode of the Chinese nation.
The mode of economic production, patriarchal relations combine with national characteristics formed the basic cultural features.

"Imagery" refers to the subjective emotion of the aesthetic subject. "Symbolize" refers to the objective aesthetic imagery." Imagery" and "Symbolize" both embody the subjective consciousness of the aesthetic subject and the object characteristics of the aesthetic object. The utility function of the aesthetic object is directly back during the use of utensils, and its shape shows the spiritual sensory experience brought about by the material production culture level, highlighting the aesthetic characteristics under the characteristics of the times. The organic combination of these aspects constitutes a complete aesthetic activity. As a perceptual existence, people and objects are attracted to each other and the material form is more aesthetically implied.

\subsection{The "Artistic Conception" of Chinese Traditional Culture}

From the perspective of creativity, the artistic conception about Chinese traditional culture is a recreation activities, it let the aesthetical products combine with designer's subjective emotion.

\subsubsection{Natural symbolic}

Chinese civilization has been accumulated for thousands of years, made Chinese people have a unique understanding of nature, and the attachments to natural worship and attachment directly affected the external appearance of the product. This design concept has been embodied in ancient people's designs. For example, applying the simple natural concept of hemispherical dome cosmology in coins directly displays the natural symbolic features, symbolizes the natural concept, and applies its "shape". In ancient times, the "Borrowing Scenery" function of doors and windows also displayed the aesthetic charm with Chinese characteristics. A large

\footnotetext{
a Corresponding author: Wu Shuang, 296767898@qq.com
} 
number of decorative patterns on the door were rich in cultural features, which not only added the formal beauty of the doors and windows, but also highlighted its cultural heritage, and shaped the "form" and "object". The combination shows the design ideas of Chinese traditional culture.

\subsubsection{Allegorical symbolic}

Chinese traditional aesthetics advocates the expression of "idea" and "image", which is different from typical figurative art in the West. The image conveys more of the cultural and philosophical value of aesthetic objects. "Book of Changes" remarked: "The apparatus is still like", and the design of utensils needs to be made on the basis of observing the images of natural things. It has a simple natural value and deep cultural connotation, and is similar to the modern western bionics, but its content the dialectical thought of Yin and Yang. Harmony of Man and Nature.

The understanding of the image by the ancients came from natural things, heaven and earth, water and fire, wind and thunder, and the natural laws of human beings. These aspects have profoundly affected China's unique aesthetic ideas. I Ching sixty-four hexagrams use "-" and "- -"simplifying all things in the world, not only embody a form of beauty, but also shows the unique thinking of the ancients on the relationship between heaven and earth. Yin-Yang thought, heaven and man thought, primal chaos thought are the important category in traditional Chinese aesthetics.

\subsubsection{Cultural aesthetic value}

Industrial design has a long history. Its origins derive from the basic needs of mankind for life. Its original purpose is to serve mankind and is the crystallization of the use of human creative thinking. Modern industrial design reflects the progress of modern science and technology, and its artistic conception expression is based on this material foundation. It also combined with traditional culture and modern design concepts. Reasonable design can make its functional elements, economic elements and cultural values unique, not only emphasizing the function of objects, but also satisfying the relationship between objects and people.

Aesthetic activities originate from social practice and are constantly changing with the development of history. Traditional culture has continuity and integrity, which deeply affects Chinese people's aesthetic sense. The beauty of artistic conception in traditional art thought is expressed through "Imagery" and "Symbolize". In popular language, "Imagery" represented creativity, cultural connotation and aesthetic value of an artwork. " Symbolize "conveyed the inner feelings of an aesthetic subject represented by utensils. The organic combination of images can form a complete aesthetic practice activity, which is also a concrete demonstration of the artistic conception in traditional culture.

Artistic beauty is unique in traditional culture, and it also provides a new way of thinking for modern design. Designers should proceed from reality, refinement and integration the quintessence in design. Embody Chinese cultural characteristics to improve the ornamental value and spiritual enjoyment.

\subsection{The essential characteristics of traditional culture}

The essence of traditional culture belongs to the category of aesthetics. It involves the subjective cognition of Chinese people's laws of nature and the aesthetic rules of artistic creation, and reflects the rich aesthetic psychology of the Chinese nation. On the whole, traditional Chinese culture pays attention to the spiritual experience that people bring in life, aesthetics, and implication.

\subsubsection{Eastern life philosophy}

Chinese culture has been polished for a long period of time to form a unique Chinese civilization. The Oriental view of life believes that all things in the entire universe and the universe have an active inner life. The eternal continuation and movement that determines this life is a kind of invisible sound, but it is everywhere in human life and nature.

"Dao" literal interpretation in Chinese means road, is orderly and regular. However, the specific trajectory and specific role of the change cannot be seen, so the "Dao" also possesses abstract features. This "nothingness" is not absent, but cannot be exhausted by the language and cannot be limited to a specific range.

"Dao" represents the basic laws of the universe and the deep understanding of life in traditional culture. "Tube Guan Zhong" said: "It's shape, don't smell its voice, and it's the order, it's the road", Song-dynasty philosophers said: "The Dao is the heart," and the Zen saying: "The heart is the Buddha." It shows that "Dao" is the core of oriental life philosophy, embodies the unique cognition of Chinese philosophy to the objective world, and presents its unique recognition of life.

Therefore, the essence of "Dao" in Chinese traditional culture is not limited to the regular changes in the material category. What it contains is more about understanding and comprehending the life of the universe. This view of life takes Dao as the basic body in the universe, and builds a humanistic universal life outlook with Chinese characteristics, which is also the essence of Chinese art. 


\subsubsection{Oriental aesthetic imagery}

In Chinese traditional culture, aesthetic image not only constitute by specific form, but also combine with related artistic symbols. What it conveys more is the sum of the artistic aesthetic sentiment conveyed by such visual images, pictures, and symbols, and the rich artistic fantasies and artistic associations that may trigger. In Chinese traditional art activities, the unique aesthetic mentality also created special aesthetic images. The artist's character, style, and accomplishment are all important requirements to achieve the aesthetic level of the works of art. .

In the works of art, the awareness of beauty can be extended to the resonance of the spiritual field through the expression of rationality, and the effect of beauty can be conveyed to become a unique eastern style aesthetic image.

\section{The necessity of introducing traditional culture into contemporary design}

\subsection{Industrial design plays an important role in society}

Industrial design combines science and technology with products to form products. It is a display of the achievements of science and technology and innovative thinking. It is also a comprehensive expression of artistic practice activities. In 1980, the International Federation of Industrial Design Associations defined the industrial design as follows: "For mass-produced products, with training, technical knowledge, experience, and visual experience, the material, structure, form, colour, surface finish, and decoration of the product are given. With new quality and specifications, and solving issues related to display, market development, etc., it is called industrial design."

Industrial design based on aesthetics, engineering, and economics, designs products and plays an important role in the socio-economic structure. In the design process, functional elements, human-computer interaction elements, shape elements, and aesthetic elements are all important links for ensuring product quality and improving product market competitiveness. Only designing products with aesthetic height and satisfying the public's psychological needs is a good design work. At the same time, industrial design also focuses on the design of product usage, safety, humanization, etc. It can be said that excellent design can greatly enhance the competitiveness and added value of products, promote the development of enterprises, and revitalize regional and national economies. Promote the sound development of productivity.

In the context of the new era, industrial design is not only the designer's self-expression art, but also a necessary means to enhance the user experience and create a brand effect. With the continuous improvement of people's living standards, the importance of industrial design is increasingly demonstrated. It can be said that industrial design, on the one hand, converts technology into market demand products, on the other hand, reflects market information to enterprises, and then promotes the development of enterprises and increases the vitality of enterprises. This is the driving force of social and economic development and the country's soft power.

\subsection{The Need for Industrial Design to Integrate with Traditional Culture}

The relationship between culture and design can reveal the purpose and motivation of design activities. The cultural connotation of design enables us to understand industrial design from a cultural perspective, thus enabling us to understand industrial design more comprehensively and deeply.

Industrial design is not a mere artistic creation, nor is it a science and technology design. It is a cultural recreation of a product. Therefore, the essence of industrial design is the cultural design of objects. Product competition is the main body of market competition. Its specific performance is the competition of design and technology. In the competition of design, after swift development of science and technology, China ignores the concern for the nature of design, and separates the product from the culture, and cannot satisfy people's spiritual pursuit. This is not only an obstacle to the development of the industrial design field, but also affects the design concept of modern products by Chinese enterprises and lacks market competitiveness.

Under this background, the industrial design of the new era should be a complex of art and technology. As a carrier of culture, it must have cultural and artistic content to satisfy people's enjoyment in the spiritual realm. This is also the culture and technology in modern society.

\subsection{The Specific Performance of Traditional Culture in Modern Furniture Design}

Furniture is closely related in our lives. It is an artistic carrier of traditional culture and can profoundly reflect human social civilization. This material 
existence and creation activity reflect social politics, economy, art, science and technology and other elements.

In modern times, people's consumption of furniture gradually shifts from purely functional demands to the satisfaction of spiritual emotions. From the perspective of furniture design, the elements of human emotion constitute the driving force of furniture consumption activities, making furniture consumption activities have more emotional colour and aesthetic imagery. Designers need to understand the new design concepts, feel the life interest, make furniture inspire the user's spiritual resonance and more aesthetic value of art

The Rose Chair is one of the traditional Chinese furniture that prevailed in the Ming Dynasty and was also loved by many people in modern times. Figure 1 shows the modern rose chair designed by Zhu Xiaojie. It respects the original shape and image of the rose chair and adopts the principle of concrete. The reinforcement is strung in a very thin column of logs and stabilized by the way of building metal structure. The cowhide cushion is manually secured to the dark wooden frame by a bright line. The overall work is very classical Chinese traditional style. The application of metal feet and steel wire extensions reveals a harmonious and comfortable modern design sense. Figure 2 is the design of the money chair, the use of concise lines to express the charm of the Ming-style chair, but it condenses the typical characteristics of traditional culture. Combined of metal and wood is a combination of modern technology and traditional culture. The multi-material mashup highlights the beauty of the work, and its design essence is rooted in Chinese traditional culture. It inherits Chinese aesthetic philosophy, combined with designer's concepts, shows more humanistic concern.

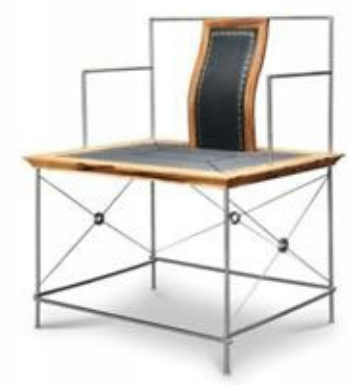

Figure 1. The rose chair

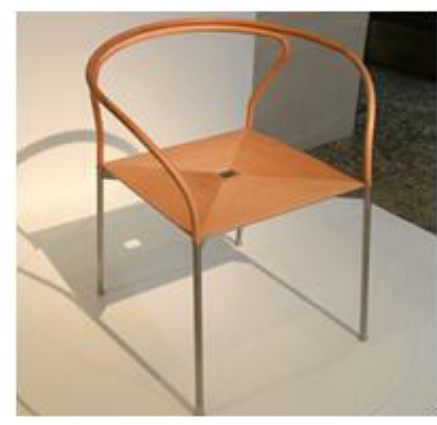

Figure 2. The money chair

\section{Creating Industrial Design with Chinese Characteristics in a New Era}

\subsection{Use traditional "object"}

To create industrial designs with Chinese characteristics in a new era, we can learn from the shapes, functions, colours, and materials of traditional beauty.

Appearance is the visual direct expression of objects, and the rational application of traditional utensils appearance features can effectively enhance the visual sensibility, thus creating a design work with Chinese cultural temperament; at the same time, the rational use of traditional decorative elements can also enhance the work from the side. The artistic aesthetic symbolism, such as traditional patterns, colours, and surface treatment methods, these elements are used as decorative means, and their own emphasis is more on the symbol of the aesthetic spirit. Therefore, appropriate reference to traditional decorative methods can also highlight Chinese characteristics in design works.

\subsection{Use traditional "meaning"}

China's traditional culture is partly disseminated with materials as its carrier, such as Ming-style armchairs, chopsticks, and various forms of artistic expression; the other part is inherited in an ideological manner, which deeply affects people's practical activities and aesthetic values.

"As a matter of metaphysics, it is shaped as a device." Artistic conception is the high-level realm pursued by traditional cultural creation ideas. Modern industrial design should draw on excellent cultural traditions, trace the beauty of artistic conception under the material elements of traditional culture, and tap its rich spiritual connotation. Fully understand the "meaning" of traditional culture, refine its cultural essence, conduct analysis, design, and re-creation, 
apply these cultural elements ingeniously, display traditional cultural and aesthetic images, and reflect the spirit of the times.

\section{Conclusion}

Under the background of the rapid development of science and technology, Chinese design should not be limited by imitating and following western design. Ignoring the country's outstanding traditional culture will make China's industrial design work in a passive and lost position under the wave of modernization and technology. Modern industrial design needs to extract elements from traditional culture, shape ethnic features, and form an independent and excellent design style so that it can stand out in the international competition.

At the same time, in the context of global development, the use of modern industrial design works and the transmission of traditional Chinese culture cannot be accompanied only by appearance and appearance, but also capture its internal aesthetic values and spiritual outlook; Industrial design not only to absorb the essence of Chinese traditional culture, but also accord with modern design concept. Not only to inherit and learn from traditional culture, but also to innovate and develop from traditional culture. Only by grasping the pulse of the times and grasping the core values can we achieve the industrial design with Chinese characteristics and give it new vitality, so that the traditional Chinese culture will regenerate in the new era and demonstrate the cultural confidence with Chinese characteristics.

\section{References}

1. Liu Guanzhong. Thinking on the structure mechanism of industrial design industry in China $[\mathrm{J}]$. Design,2013(10):158-163

2. Wang Zhenfu.The beauty of great ease[M]. Peking University Press,2006:123-125

3. Li Zehou.Chinese Aesthetics[M]. Guangxi Normal University press, $2002: 57-58$

4. Zong Baihua.Aesthetics and artistic conception[M]. Chinese People's Publishing House, 1987 : 156-171

5. Wang Shouzhi.History of world industrial design[M].China Youth Publishing House,2002 :3035 